\title{
The Impact of the Private Sector Co-Payment Mechanism (PSCM) on the Private Market for ACTs in Nigeria: Results of the 2018 Cross-sectional Outlet and Household Market Surveys.
}

Hannah M. Edwards ( $\square$ hannah.edwards11@imperial.ac.uk)

Malaria Consortium https://orcid.org/0000-0001-8706-0732

Rubaiyath Sarwar

Innovision

Parvez Mahmud

Innovision

Shekarau Emmanuel

National Malaria Elimination Programme

Kolawole Maxwell

Malaria Consortium

James K. Tibenderana

Malaria Consortium

\section{Research}

Keywords: Private sector healthcare, case management, health economics, malaria control, informal health workers, private sector engagement, targeted subsidy, artemisinin-based combination therapy, private sector copayment mechanism

Posted Date: September 27th, 2021

DOI: https://doi.org/10.21203/rs.3.rs-917449/v1

License: (9) This work is licensed under a Creative Commons Attribution 4.0 International License. Read Full License

Version of Record: A version of this preprint was published at Malaria Journal on February 12th, 2022. See the published version at https://doi.org/10.1186/s12936-021-04039-9. 


\section{Abstract}

\section{Background}

The private sector plays a large role in malaria treatment provision in Nigeria. To improve access to, and affordability of, quality-assured artemisinin combination therapies (QA-ACTs) within this sector, the Affordable Medicines Facility - Malaria began operations in 2010 and transitioned to a private sector co-payment mechanism (PSCM) until 2017. To assess the impact of the scheme on the ACT market, cross-sectional household and outlet surveys were conducted in 2018 to coincide with the final stockages of ACTs procured under the PSCM.

\section{Methods}

An outlet survey was conducted targeting private pharmacies and Proprietary and Patent Medicine Vendors (PPMVs) across different regions of Nigeria to assess supply-side market factors related to availability and cost of antimalarials, including ACTs subsidised under the PSCM (called green leaf ACTs on account of their green leaf logo) and those not subsidised (non-green leaf ACTs). A concurrent household survey was conducted to determine demand-side factors related to treatment seeking practices, ACT brand preference and purchase decision. Data were compared with previous ACTWatch surveys to consider change over time.

\section{Results}

Availability of ACTs increased significantly over the PSCM period and was almost universal by the time of the 2018 market survey. This increase was seen particularly among PPMVs. While the cost of green leaf ACTs remained relatively stable over time, the cost of non-green leaf ACTs reduced significantly so that by 2018 they had equivalent affordability. Unsubsidised brands were also available in different formulations and dosages, with double-strength ACTs reported as the most frequently purchased dosage type, and child ACTs popular in suspension and dispersible forms (forms not subsidised by the PSCM).

\section{Conclusions}

The PSCM had a clear impact on increasing not only the reach of subsidised QA brands, but also of nonsubsidised brands. Increased market competition led to innovation from unsubsidised brands and large reductions in costs to make them competitive with subsidised brands. Concerns are drawn from the large market share that non-QA brands have managed to gain as well as the continued market share of oral artemisinin monotherapies. Continued monitoring of the market is recommended, along with improved local capacity for QA-certification and monitoring.

\section{Background}

Appropriate and timely case management is an essential component in any successful malaria control programme. Over recent years there has been emphasis on promotion of malaria diagnostic testing to replace presumptive treatment, followed by appropriate treatment with artemisinin combination therapy (ACT) in response to a positive test result [1]. Point-of-care rapid diagnostic tests (RDTs) have made this increasingly possible since they are cheap and easy to administer by healthcare workers, community volunteers or private 
providers with minimal training, while quality-assured ACTs (QA-ACTs) ensure thorough elimination of the parasite from the blood stream [2]. Poor quality or incorrect drug regimens, including use of monotherapies, can lead to failure of treatment for the individual and increase drug resistance pressure on the parasite $[3,4]$.

Ensuring high coverage and implementation of this case management pathway has proved difficult in many endemic countries, however. Many populations most afflicted with malaria are in remote rural areas with limited access to health facilities [5-7]. These populations are often served by a variety of healthcare providers including public health facilities, private hospitals, pharmacies, drug stores and roaming traders [8]. While public health care provision can be controlled and monitored by national malaria control programmes, private channels are often unregulated and case management practices unsupervised. There is increasing recognition that in order to reach many population groups, engagement with the private sector is needed in order to harmonise diagnostic and treatment methods, reduce the prevalence of sub-standard and counterfeit drugs, and ensure the removal of mono-artemisinin drugs and other antimalarials no longer recommended as first-line treatment $[9,10]$.

To overcome some of these issues, a financing mechanism called the Affordable Medicines Facility - Malaria (AMFm) was launched in 2010 with funding from the Global Fund to Fight AIDS, Tuberculosis \& Malaria (GFATM), and later transitioned to the Private Sector Co-payment Mechanism (PSCM) with operations running until 2017. Herein, the term PSCM will be used to refer to the period 2010-2017 under which these financing mechanisms were in operation. The PSCM's aim was to subsidise the cost of QA-ACTs that had been through the World Health Organization's (WHO's) pre-qualification certification programme thereby increasing the use of pre-qualified ACTs (PQ-ACTs) and crowd out monotherapies [11]. Specific interventions included i) negotiating price reductions from manufacturers to private-sector importers/first-line buyers (FLBs), ii) subsidising the cost of the ACTs from manufacturers to further reduce costs to FLBs, and iii) supporting interventions to promote appropriate ACT use, such as training and behaviour change communication for private sector vendors [12]. Ultimately, these interventions aimed to increase affordability of QA-ACTs and, in turn, increase consumer access and uptake through the private sector [13]. The subsidised PQ-ACTs were marked with a 'green leaf' logo to aid identification and market promotion (herein referred to as "green leaf ACTs") [12].

Nigeria, a country with a national malaria prevalence in children aged 6-59 months of $23 \%$ in 2018 (although with high heterogeneity between states), has a large private sector pharmaceutical market [14]. During the PSCM implementation period, regular ACTWatch surveys were conducted which showed the availability of green leaf ACTs increased from $8.7 \%$ in 2011 to $17.7 \%$ in 2015 across all private sector providers, though this was most marked among drug stores, also known as Proprietary and Patent Medicine Vendors (PPMVs), where availability rose from $49.4-78.8 \%[15]$.

The final ACTWatch survey was carried out in 2015, whereas the PSCM terminated in Nigeria in 2018. Furthermore, the ACTWatch surveys were only targeted at health providers and outlets and thus only assessed supply-side market indicators; they did not provide information on market demand from consumers. To assess the state of the private-sector RDT and ACT market in Nigeria at the end of the PSCM a national outlet survey of private pharmacies and PPMVs was conducted along with a nationwide household survey to assess both supply and demand side impact of the PSCM. Whereas pharmacies are run by trained health professionals, a PPMV is defined as 'a person without formal training in pharmacy who sells orthodox pharmaceutical products 
on a retail basis for profit' [16]. These two outlet types play a significant role in diagnostic and treatment provision in Nigeria but are unregulated and thus are a key focus for private-public-partnership engagement. The surveys were also designed to provide a baseline assessment from which the market could be monitored once the subsidy scheme had been removed. Here, we present the results of these surveys specifically in relation to the impact on the private-sector ACT market, including impact on both the supply (outlet) and demand (household) sides of the market.

\section{Methods}

Two cross-sectional surveys - an outlet survey and a household survey - were conducted nationwide in Nigeria in 2018 at the end of the PSCM. The aim was to assess both demand and supply side market systems via a quantitative approach.

Supply side analysis: Outlet survey

The objective of the outlet survey was to ascertain the current status of ACT availability, gaps in the market, market share and prices of different antimalarial brands. The survey was targeted to both PPMVs and pharmacies in the private retail sector, and sampling was conducted to cover the six states of Nigeria representing the six geo-political zones (North-Central, North-East, North-West, South-South, South-West, SouthEast) as well as different malaria endemicities. PPMV and pharmacy staff completed face-to-face questionnaires with the survey team to collect information in regard to antimalarial stock, price, brand awareness and consumer preference, as well as knowledge of the green leaf logo.

Sampling strategy

Since the total number of providers was unknown, sample size was determined assuming the population size to be $>20,000$ (or unknown), with a $50 \%$ response rate, $5 \%$ margin of error and $95 \%$ confidence level and a design effect of 2. This estimated a sample size of 768 outlets for the survey. All the states in Nigeria were segregated into four groups based on the prevalence of malaria to ensure representation across the four malaria endemic zones - Group 1: 0-10\% prevalence, Group 2: 10-30\% prevalence, Group 3: $30-50 \%$ prevalence, and Group 4: >50\% prevalence. The population size of each malaria endemic zone was calculated by summing the population size of all the states within each group. The sample size of outlets for each group was then split based on the ratio of the population in each group compared to the total population of all groups (Table 1).

To ensure representation of the six geo-political zones (and thus the different socio-economic and political contexts) in Nigeria, one state from each geo-political zone was selected. Since malaria endemic group 2 represented $50 \%$ of the total population of Nigeria three states were allocated for selection to this group and one state for each of the other groups. States were randomly selected and once a state was selected from a particular geo-political zone, that zone was removed from the randomization and the next state selected. The final states selected were Kano, Gombe, Kogi, Imo, Edo and Osun (Fig. 1, Table 1).

Once states had been selected, a list of local government authority (LGAs) was generated for each state and one LGA was randomly selected per state. The second LGA was purposively selected to ensure an urban/rural 
split and sampling of LGAs that were within a proximate location of one another. For example, if a rural LGA was randomly selected, then a nearby urban LGA was purposively selected, and vice versa. It was expected that urban LGAs would have a greater number of pharmacies relative to PPMVs, while rural LGAs would have greater number of PPMVs. Hence the sample size for each state was split to survey $50 \%$ from urban LGAs and $50 \%$ from rural LGAs, and within urban sites to include $70 \%$ pharmacies and $30 \%$ PPMVs, while in rural sites to include $70 \%$ PPMVs and $30 \%$ pharmacies.

Table 1

Outlet and Household survey sampling locations and sample size across selected groups, including planned sample size and actual sample size achieved.

\begin{tabular}{|c|c|c|c|c|c|c|}
\hline \multicolumn{7}{|c|}{ Outlet survey sample } \\
\hline $\begin{array}{l}\text { Malaria } \\
\text { endemic } \\
\text { group }\end{array}$ & $\begin{array}{l}\text { \# total } \\
\text { states } \\
\text { nationwide }\end{array}$ & 2018 Population & $\begin{array}{l}\% \text { total } \\
\text { population }\end{array}$ & $\begin{array}{l}\text { Outlet sample } \\
\text { size (planned) }\end{array}$ & $\begin{array}{l}\text { Selected } \\
\text { state(s) }\end{array}$ & $\begin{array}{l}\text { Sample } \\
\text { size } \\
\text { achieved }\end{array}$ \\
\hline $\begin{array}{l}\text { Group 1: } \\
\text { 0-10\% }\end{array}$ & 2 & $19,086,824$ & 10 & 75 & Imo & 77 \\
\hline \multirow{3}{*}{$\begin{array}{l}\text { Group 2: } \\
10-30 \%\end{array}$} & \multirow[t]{3}{*}{24} & \multirow[t]{3}{*}{$114,617,062$} & \multirow[t]{3}{*}{59} & \multirow[t]{3}{*}{449} & Kogi & \multirow[t]{3}{*}{406} \\
\hline & & & & & Gombe & \\
\hline & & & & & Osun & \\
\hline $\begin{array}{l}\text { Group 3: } \\
30-50 \%\end{array}$ & 8 & $48,204,958$ & 25 & 189 & Kano & 155 \\
\hline $\begin{array}{l}\text { Group 4: } \\
>50 \%\end{array}$ & 3 & $14,014,062$ & 7 & 55 & Edo & 57 \\
\hline Total & 37 & $195,922,906$ & 100 & 768 & & 695 \\
\hline \multicolumn{7}{|c|}{ HH survey sample } \\
\hline $\begin{array}{l}\text { Malaria } \\
\text { endemic } \\
\text { group }\end{array}$ & $\begin{array}{l}\text { Selected } \\
\text { state }\end{array}$ & $\begin{array}{l}\% \text { state } \\
\text { population/total } \\
\text { population }\end{array}$ & $\begin{array}{l}\text { Sample } \\
\text { size } \\
\text { planned }\end{array}$ & $\begin{array}{l}\text { Sample size } \\
\text { achieved }\end{array}$ & & \\
\hline $0-10$ & Imo & 21 & 80 & 90 & & \\
\hline $10-30$ & Gombe & 12 & 45 & 75 & & \\
\hline $30-50$ & Kano & 51 & 196 & 233 & & \\
\hline$>50$ & Edo & 16 & 63 & 81 & & \\
\hline Total & 100 & 100 & 384 & 479 & & \\
\hline
\end{tabular}

Demand side analysis: Household survey

The objective of the HH survey was to determine $\mathrm{HH}$ use of the private sector, demand for ACTs, brand preference and factors affecting purchase decision. The survey focused exclusively on low-income households in both urban and rural areas of Nigeria. Purposive sampling of three low-income segments was conducted including HHs with monthly incomes of: 1) NGN $\leq 18000$, 2) NGN 18,001-36,000, 3) NGN 36,001-100,000. For 
comparative analysis, a small number of samples from HHs with monthly income NGN > 100,000 were also collected. Questionnaires were delivered to heads of households to collect data on diagnosis and treatment seeking behaviours, ACT brand preference, willingness to pay and knowledge of green-leaf ACTs and fake ACTs.

Sampling strategy

The total population of the three income segments was unknown, therefore, sample size was calculated assuming an unknown population size, $50 \%$ response rate, $5 \%$ margin of error and $95 \%$ confidence level to derive a sample size of 384 (Table 1).

$\mathrm{HHs}$ were selected from four of the six states included in the outlet survey so as to represent each of the four malaria endemic zones in Nigeria and make the survey comparable with the outlet survey. Thus, the state representing Group 2 was randomly selected from the three included in the outlet survey. The final states included for the HH survey were Imo, Edo, Gombe and Kano (Fig. 1). The sample size was distributed across the four selected states according to the same ratio as the size of the state population compared to the total population size of all four states combined (Table 1). The sample per state was planned to be split $50 \%$ urban and $50 \%$ rural. Purposive sampling was conducted to place $50 \%$ of the sample from income segment 1 ) NGN $\leq 18000,35 \%$ from income segment 2) NGN 18,001-36,000, and 15\% from income segment 3) NGN 36,001100,000 .

Data Collection and quality assurance

Data for both surveys was collected digitally through tablet phones on digitized questionnaires using the LimeSurvey software v2 [17]. Data uploaded to the server were checked daily for consistency and discrepancies. If errors were identified these were immediately notified to the field survey teams to rectify. In addition, quality assurance spot-checks were conducted randomly by survey supervisors to ensure data collection protocols were followed accurately. Random checks were conducted on $10 \%$ of all samples. Data was downloaded in excel format and transferred to SPSS [18] and R [19] for analysis.

\section{Data analysis}

Data from the outlet survey were analysed to retrieve proportions and 95\% confidence intervals (Cl) for key indicators relating to the availability of antimalarial drugs, brand coverage and consumer preference.

Availability was defined as the percentage of outlets with antimalarial/ACT in stock at the time of the survey. Analyses were conducted overall as well as by subgroup, including outlet type (pharmacy or PPMV), region (north or south) or area (urban or rural). Kano, Gombe and Kogi were grouped as northern states and Osun, Edo and Imo were grouped as southern states. Data from the household survey were analysed similarly to gather information on diagnostic and treatment seeking practices, awareness of ACTs, brand preference and factors influencing purchase decision, with subgroup analysis by region, area and $\mathrm{HH}$ monthly income. Where appropriate, proportions between sub-groups were compared using a binomial test for difference in proportions or a chi-square test for trend, and p-values significant at the $p=0.05$ level are presented.

To assess the impact of the PSCM on different drug types in the market, antimalarial brands were analysed based on the following grouping: 1) green leaf ACTs (i.e. PQ-ACTs with the green leaf logo) - these ACTs are 
those directly subsidised under the PSCM, 2) non-green leaf ACTs - these ACTs contain both PQ and non-PQ ACTs, as well as QA and non-QA ACTs, but all are ACTs that have not been directly subsidised under the PSCM, and 3) non-ACT antimalarials - which includes both QA and non-QA antimalarials (see supplementary information for a full brand list in each category). It was anticipated that while analysis of green leaf ACTs would show the direct impact of the subsidy scheme, the other categories would highlight indirect effects on the wider antimalarial market. For analysis of specific brands, we labelled non-green leaf ACTs into those that were PQ or QA versus those that were not since the latter may present an issue for good case management practices (it is thus important to monitor the market for these).

In order to assess the impact of the PSCM over time, antimalarial and ACT coverage figures among PPMVs and pharmacies were compared to those from previous ACTWatch surveys conducted in 2009, 2011, 2013 and 2015 [15]. Raw data from the ACTWatch surveys were extracted for pharmacies and PPMVs (referred to as 'drug stores' in the ACTWatch reports) only in order to make indicators comparable [20]. For each indicator, a chi-square test for trend was used to indicate any significant change in coverage over time.

\section{Results}

The final outlet survey sample included 695 outlets including 321 (46.2\%) pharmacies and 374 (53.8\%) PPMVs. Split by region and area, $59.3 \%$ of outlets were from northern states $(n=412)$ and $65.0 \%$ were from urban areas $(n=452)$. The actual sample size of outlets achieved in the field differed to the planned sample size because of unavailability of pharmacies in rural areas; from a planned 116 pharmacies in rural areas, only 36 were sampled. Furthermore, only 207 PPMVs were sampled in rural areas compared to the 270 originally planned. Population and coverage of PPMVs and pharmacies was much lower in rural areas than anticipated, thus, the actual sample size achieved is representative of the actual field scenario. In contrast, urban areas achieved a greater sample size than planned due to the higher number of pharmacies and PPMVs available to urban areas than expected, again making the final sample representative of the situation on the ground (285 urban pharmacies were sampled compared to 270 originally planned, and 167 PPMVs were sampled compared to an original 116 planned).

The final HH survey covered a total of $479 \mathrm{HHs}$ nationwide, with $64.3 \%(n=308)$ in northern states and $54.1 \%$ $(n=259)$ in urban areas. The planned sample size was rounded up to 479 in the field for convenience and to account for $\mathrm{HH}$ non-response, as well as to include $24 \mathrm{HHs}$ with income NGN > 100,000 per month. The sample size achieved per income segment was 44\% NGN < 18,000 ( $n=211), 35 \%$ NGN 18,001-36,000 ( $n=167), 16 \%$ NGN 36,001-100,000 ( $n=77)$ and $5 \%$ NGN > 100,000 ( $n=24)$.

Supply-side: Outlet survey results

Availability of ACTs

Outlet availability of antimalarials (including any antimalarial) and ACTs (including any ACT) was almost universal at 99.6\% [95\% Cl 98.7-99.9] and 97.6\% [95\% Cl 96.1-98.6], respectively, while coverage of green leaf ACTs was very high at $80.7 \%, 95 \% \mathrm{Cl}$ [77.6-83.6] (Fig. 2). There were significantly more pharmacies than PPMVs with ACTs in stock $(p<0.05)$ though there was no difference in the stockage of green leaf ACTs (Fig. 2A). 
Split by region, availability of ACTs was significantly higher in southern PPMVs compared to northern PPMVs $(p<0.05)$, and coverage of green leaf ACTs was significantly higher in the southern states for both outlet types $(p<0.001$, Fig. 2B). Green leaf ACTs also had significantly higher coverage in rural pharmacies compared to urban pharmacies $(p<0.05$, Fig. 2 C).

To determine how availability of the different antimalarial types had changed over time, availability was compared to previous ACTWatch survey data for pharmacies and PPMVs. Availability of antimalarials in general had remained high throughout the survey years, but the availability of ACTs and green leaf ACTs significantly increased from the first ACTWatch surveys in 2009/2011 to the 2018 market survey (Fig. 3). Availability of ACTs increased between each survey round from 56.0\%, 95\% Cl [53.4-58.6] in 2009, to 97.6\%, 95\% Cl [96.1-98.6] in 2018 (chi-square test for trend in proportions: $X^{2}=665.86, d f=1, p<0.001$, Fig. 3A). Availability of green leaf ACTs increased from 54.2\%, 95\% Cl [51.3-57.0] in 2011 (Greenleaf ACTs were not in circulation during the 2009 survey round) to $80.7 \%, 95 \% \mathrm{Cl}$ [77.6-83.6] in 2018 (Chi-square test for trend: $\mathrm{X}^{2}=$ $230.63, \mathrm{df}=1, \mathrm{p}<0.001$ ), although there was a plateauing from 2015 where the availability was $78.0 \%, 95 \% \mathrm{Cl}$ [76.5-79.5], Fig. 3A.

Analysis of outlet types separately shows this change over time was among PPMVs, whose coverage of ACTs and green leaf ACTs increased significantly over the survey years, while pharmacies showed no significant change in any drug category (Fig. 3B and 3C). Among PPMVs, coverage of ACTs increased from $40.5 \%, 95 \% \mathrm{Cl}$ [37.5-43.6] in 2009, to 96.3\%, 95\% Cl [93.8-97.9] in $2018\left(X^{2}=783.37\right.$, df = 1, p < 0.001$)$, and coverage of green leaf increased from $53.1 \%, 95 \% \mathrm{Cl}[50.2-56.0]$ in 2011 to $79.4 \%, 95 \% \mathrm{Cl}[75.0-83.4]\left(X^{2}=213.15, \mathrm{df}=1, \mathrm{p}<\right.$ 0.001 ) in 2018.

Availability and market share of specific ACT brands

Among all outlets, the most frequently stocked antimalarial was the non-green leaf ACT (and non-QA ACT), Lonart (53\%). This was followed by the non-ACT antimalarial, Fansidar (51\%) and another non-green leaf ACT (and non-QA ACT), P-Alaxin (47\%). The most available green leaf ACTs were Combisunate (45\%) and Coartem (41\%) (Fig. 4A).

Brands top in availability were similar to those reported as top-selling and thus having the highest market share. The non-green leaf ACT, Lonart, was named in the top-5 selling brands of antimalarial by $43.2 \%$ of outlets, followed by Coartem in $34.2 \%$ of outlets and P-Alaxin in $27.5 \%$ (Fig. 4B). Coartem was followed by Combisunate as the second top-selling green leaf ACT (27.2\%). The top-5 selling brands thus included two green leaf ACTs, two non-green leaf ACTs and one mono-artemisinin (Amalar). Mono-artemisinins made up four of the top-10 brands, however, and four of the top-brands were non-QA.

Availability and market share of different antimalarial formulations

Of all the antimalarials in stock at the time of the survey, the vast majority were in tablet form (88.2\%), with some in suspension (4.3\%), syrup (5.8\%), and dispersible (1.6\%) formulations. Of all the tablets in stock, $49.9 \%$ were available as double strength dosage (80/480), compared to $34.8 \%$ available as standard strength (20/120) and $15.4 \%$ as $40 / 240$ strength. Double-strength ACTs (80/480) were reported by outlet staff to have greater availability than single-strength ACTs (20/120) despite the latter type being the form supplied under the 
PSCM scheme. Providers estimated that double-strength ACTs took up $44 \%$ of available stock, compared to $35 \%$ for single-strength ACTs, $11 \%$ for $40 / 240$ dosage drugs and $10 \%$ for suspension formulations.

Of the top- 5 selling brands, the green-leaf antimalarials, Combisunate and Coartem, were supplied as standard strength tablets, while Lonart was available as both standard strength and double strength dosages (6 tablets) for adults, as well as in suspension and dispersible forms for children, and P-Alaxin was in a double-strength form (6 tablets) for adults, and suspension and syrup forms for children.

Sales price

Prices of ACTs were reported to be volatile by providers, with almost half saying the price would change every quarter or every six months ( $24 \%$ quarterly, $24 \%$ six-monthly). Over $60 \%$ of providers also stated that the price had been more volatile over the past year compared to the previous year. The Naira devaluation, ACT scarcity and distributor margins were reported as highly significant contributors to the volatility of prices among $75 \%$, $58 \%$ and $49 \%$ of respondents, respectively.

There was wide disparity in price depending on the brand, type (green leaf, non-green leaf and non-ACTs) and pack size (Table 2). Green leaf brands under the PSCM had a median cost of NGN 600, ranging from NGN 350 for Combisunate to NGN 600 for Lumartem, all with 24 tablet formulations. The cost of non-green leaf ACTs varied widely depending on the formulation. The standard-strength ACTs ( 24 tablets) had a median cost of NGN 500, making them more affordable than the green leaf ACTs, while double-strength dosages (6 or 9 tablets) cost on average NGN 900. The double-strength dosages showed wide variation, however, ranging from NGN 550 for Combisunate DS to NGN 1650 for Coartem DS. The non-ACT antimalarials were much cheaper with a median price of NGN 180 for three or nine tablets. Overall prices were generally cheaper among PPMVs, in northern states and in rural areas.

Child dosages were generally slightly cheaper compared to adult dosages and came in a variety of pack sizes (Table 3). In addition, some ACT brands offered child dosages in suspension, dispersible and/or syrup formulations (Table 4). Suspension formulations were more expensive compared to other formulations at an average of NGN 800, but dispersible and syrup formulations were comparable to standard tablets (average cost at NGN 300 and NGN 450, respectively). These alternative forms are not part of the PSCM scheme. 
Table 2

Median price of adult dosages in tablet form among the different antimalarial brands in outlets disaggregated by region (north-south), area (rural-urban) and outlet type (pharmacy-PPMV) as well as by type of antimalarial.

\section{Median cost (NGN)}

\begin{tabular}{|c|c|c|c|c|c|c|c|c|c|}
\hline Brand name & Type & $\begin{array}{l}\# \\
\text { tablets } \\
\text { in } \\
\text { AETD }\end{array}$ & North & South & Rural & Urban & $\begin{array}{l}\text { Pharm- } \\
\text { acy }\end{array}$ & PPMV & $\begin{array}{l}\text { Average } \\
\text { cost of } \\
\text { brand/ } \\
\text { type } \\
\text { overall }\end{array}$ \\
\hline Amalar & $\begin{array}{l}\text { Non-ACT } \\
\text { antimalarial }\end{array}$ & 3 & 150 & 180 & 200 & 150 & 150 & 180 & 170 \\
\hline Amalar Plus & $\begin{array}{l}\text { Non-ACT } \\
\text { antimalarial }\end{array}$ & 9 & 325 & 300 & 400 & 300 & 350 & 300 & 300 \\
\hline Camosunate & $\begin{array}{l}\text { Non-green } \\
\text { leaf ACT } \\
\text { (ds) }\end{array}$ & 6 & 600 & 600 & 525 & 600 & 600 & 500 & 600 \\
\hline Coartem & $\begin{array}{l}\text { Green leaf } \\
\text { ACT }\end{array}$ & 24 & 350 & 600 & 480 & 600 & 600 & 490 & 500 \\
\hline Coartem DS & $\begin{array}{l}\text { Non-green } \\
\text { leaf ACT } \\
\text { (ds) }\end{array}$ & 6 & 1,650 & 1,600 & 1,700 & 1,650 & 1,600 & 1,800 & 1,650 \\
\hline Combisunate & $\begin{array}{l}\text { Green leaf } \\
\text { ACT }\end{array}$ & 24 & 300 & 400 & 350 & 330 & 330 & 350 & 350 \\
\hline $\begin{array}{l}\text { Combisunate } \\
\text { DS }\end{array}$ & $\begin{array}{l}\text { Non-green } \\
\text { leaf ACT } \\
\text { (ds) }\end{array}$ & 6 & 500 & 550 & 500 & 600 & 600 & 550 & 550 \\
\hline Lonart & $\begin{array}{l}\text { Non-green } \\
\text { leaf ACT } \\
\text { (ss) }\end{array}$ & 24 & 500 & 500 & 500 & 500 & 500 & 500 & 500 \\
\hline Lonart DS & $\begin{array}{l}\text { Non-green } \\
\text { leaf ACT } \\
\text { (ds) }\end{array}$ & 6 & 1,100 & 1,200 & 1,000 & 1,200 & 1,200 & 1,100 & 1,200 \\
\hline Lumartem & $\begin{array}{l}\text { Green leaf } \\
\text { ACT }\end{array}$ & 24 & 350 & 600 & 600 & 600 & 650 & 600 & 600 \\
\hline P-Alaxin & $\begin{array}{l}\text { Non-green } \\
\text { leaf ACT } \\
\text { (ds) }\end{array}$ & 9 & 800 & 850 & 800 & 850 & 850 & 800 & 845 \\
\hline \multirow{3}{*}{$\begin{array}{l}\text { Median by } \\
\text { type: }\end{array}$} & All brands & & 550 & 650 & 500 & 700 & 718 & 500 & 600 \\
\hline & $\begin{array}{l}\text { Green leaf } \\
\text { ACT }\end{array}$ & & 350 & 600 & 450 & 600 & 600 & 450 & 500 \\
\hline & $\begin{array}{l}\text { Non-ACT } \\
\text { antimalarial }\end{array}$ & & 150 & 200 & 200 & 170 & 155 & 200 & 180 \\
\hline
\end{tabular}




\begin{tabular}{|c|c|c|c|c|c|c|c|}
\hline & Media & $\operatorname{cost}($ & & & & & \\
\hline $\begin{array}{l}\text { Non-green } \\
\text { leaf ACT } \\
\text { (ds) }\end{array}$ & 1000 & 865 & 800 & 950 & 950 & 800 & 900 \\
\hline $\begin{array}{l}\text { Non-green } \\
\text { leaf ACT } \\
\text { (ss) }\end{array}$ & 500 & 500 & 500 & 500 & 500 & 500 & 500 \\
\hline $\begin{array}{l}\text { AETD = adult equivalent treatment dose } \\
d s=\text { double-strength } \\
\text { ss = standard-strength }\end{array}$ & & & & & & & \\
\hline
\end{tabular}

Table 3

Median price of child dosages in tablet form among the different antimalarial brands in outlets disaggregated by region (north-south), area (rural-urban) and outlet type (pharmacy-PPMV).

\begin{tabular}{|c|c|c|c|c|c|c|c|c|c|}
\hline \multirow[b]{2}{*}{ Brand name } & \multirow[b]{2}{*}{ Type } & \multirow[b]{2}{*}{$\begin{array}{l}\# \\
\text { tablets } \\
\text { in pack }\end{array}$} & \multicolumn{6}{|c|}{ Median cost (NGN) } & \multirow[b]{2}{*}{$\begin{array}{l}\text { Average } \\
\text { cost of } \\
\text { brand } \\
\text { overall }\end{array}$} \\
\hline & & & North & South & Rural & Urban & Pharmacy & PPMV & \\
\hline \multirow[t]{3}{*}{ Coartem } & \multirow{3}{*}{$\begin{array}{l}\text { Green } \\
\text { leaf } \\
\text { ACT }\end{array}$} & 6 & 150 & 150 & 135 & 150 & 150 & 150 & 150 \\
\hline & & 12 & 200 & 250 & 250 & 225 & 200 & 250 & 250 \\
\hline & & 18 & 300 & 350 & 300 & 300 & 300 & 300 & 300 \\
\hline Coartem DS & $\begin{array}{l}\text { Non- } \\
\text { green } \\
\text { leaf } \\
\text { ACT } \\
\text { (ds) }\end{array}$ & 6 & 1700 & . & & 1700 & 1700 & . & 1700 \\
\hline \multirow[t]{3}{*}{ Combisunate } & \multirow{3}{*}{$\begin{array}{l}\text { Green } \\
\text { leaf } \\
\text { ACT }\end{array}$} & 6 & 110 & 150 & 150 & 140 & 140 & 150 & 150 \\
\hline & & 12 & 200 & 250 & 250 & 250 & 250 & 250 & 250 \\
\hline & & 18 & 300 & 300 & 300 & 300 & 300 & 300 & 300 \\
\hline $\begin{array}{l}\text { Combisunate } \\
\text { DS }\end{array}$ & $\begin{array}{l}\text { Non- } \\
\text { green } \\
\text { leaf } \\
\text { ACT } \\
\text { (ds) }\end{array}$ & 6 & 600 & 600 & 550 & 600 & 600 & 550 & 600 \\
\hline \multirow[t]{3}{*}{ Lumartem } & \multirow{3}{*}{$\begin{array}{l}\text { Green } \\
\text { leaf } \\
\text { ACT }\end{array}$} & 6 & 100 & 150 & 110 & 150 & 125 & 135 & 135 \\
\hline & & 12 & 225 & 250 & 250 & 250 & 250 & 250 & 250 \\
\hline & & 18 & 300 & 350 & 350 & 350 & 350 & 350 & 350 \\
\hline
\end{tabular}


Table 4

Median price of child dosages in alternative forms (suspension, syrup and dispersible) among the different antimalarial brands in outlets disaggregated by region (north-south), area (rural-urban) and outlet type (pharmacy-PPMV).

\begin{tabular}{|c|c|c|c|c|c|c|c|c|}
\hline & & Media & $\operatorname{cost}(\mathrm{NC}$ & & & & & \\
\hline Brand name & Formulation & North & South & Rural & Urban & Pharmacy & PPMV & $\begin{array}{l}\text { Average cost of } \\
\text { brand/form } \\
\text { overall }\end{array}$ \\
\hline \multirow[t]{3}{*}{ Coartem } & Suspension & 350 & 350 & 350 & 325 & 350 & 350 & 350 \\
\hline & Syrup & 400 & 480 & 440 & 450 & 450 & 440 & 440 \\
\hline & Dispersible & 400 & 250 & 250 & 300 & 275 & 275 & 275 \\
\hline \multirow[t]{2}{*}{ Lonart } & Suspension & 800 & 900 & 800 & 850 & 900 & 800 & 850 \\
\hline & Dispersible & 225 & 300 & 275 & 300 & 300 & 300 & 300 \\
\hline Lonart DS & Suspension & 850 & 875 & 850 & 875 & 875 & 850 & 850 \\
\hline \multirow[t]{2}{*}{ P-Alaxin } & Suspension & 700 & 750 & 700 & 750 & 750 & 700 & 700 \\
\hline & Syrup & . & 450 & . & 450 & . & 450 & 450 \\
\hline \multirow{3}{*}{$\begin{array}{l}\text { Median by } \\
\text { form: }\end{array}$} & Suspension & 750 & 800 & 700 & 800 & 800 & 700 & 800 \\
\hline & Syrup & 400 & 465 & 440 & 450 & 450 & 450 & 450 \\
\hline & Dispersible & 250 & 300 & 250 & 300 & 300 & 300 & 300 \\
\hline
\end{tabular}


Table 5

Median retail price of the different types of antimalarials across the different surveys among pharmacies and PPMVs.

\begin{tabular}{|c|c|c|c|c|c|c|c|}
\hline & \multirow[b]{2}{*}{$\begin{array}{l}\text { Survey } \\
\text { year }\end{array}$} & \multicolumn{2}{|c|}{$\begin{array}{l}\text { Median retail price } \\
\text { (USD) }^{\dagger}\end{array}$} & \multicolumn{2}{|c|}{$\begin{array}{l}\% \text { price change on } \\
\text { previous year }\end{array}$} & \multicolumn{2}{|c|}{$\begin{array}{l}\text { \% price change 2011-2018 } \\
\text { (start-end PSCM) }\end{array}$} \\
\hline & & Pharmacy & PPMV & Pharmacy & PPMV & Pharmacy & PPMV \\
\hline \multirow{5}{*}{$\begin{array}{l}\text { Green leaf } \\
\text { ACTs* }\end{array}$} & 2009 & na & na & & & & \\
\hline & 2011 & 0.91 & 0.78 & & & & \\
\hline & 2013 & 1.59 & 0.95 & 74.7 & 22.3 & & \\
\hline & 2015 & 1.56 & 1.30 & -1.9 & 36.3 & & \\
\hline & 2018 & 1.47 & 1.63 & -5.7 & 25.7 & 61.6 & 109.5 \\
\hline \multirow{5}{*}{$\begin{array}{l}\text { Non-green leaf } \\
\text { ACTs } \\
\text { (ss only*) }\end{array}$} & 2009 & 4.55 & 4.22 & & & & \\
\hline & 2011 & 3.74 & 3.90 & -17.9 & -7.7 & & \\
\hline & 2013 & 4.45 & 3.81 & 19.1 & -2.2 & & \\
\hline & 2015 & 3.38 & 3.38 & -24.1 & -11.4 & & \\
\hline & 2018 & 1.63 & 1.63 & -51.6 & -51.6 & -56.3 & -58.1 \\
\hline \multirow{5}{*}{$\begin{array}{l}\text { Non-green leaf } \\
\text { ACTs } \\
\text { (ds only*) }\end{array}$} & 2009 & 3.77 & 3.83 & & & & \\
\hline & 2011 & 2.92 & 3.57 & -22.4 & -6.8 & & \\
\hline & 2013 & 3.97 & 3.81 & 35.9 & 6.7 & & \\
\hline & 2015 & 3.64 & 3.64 & -8.4 & -4.6 & & \\
\hline & 2018 & 2.61 & 2.94 & -28.2 & -19.2 & -10.6 & -17.7 \\
\hline \multirow{5}{*}{$\begin{array}{l}\text { Non-ACT } \\
\text { antimalarials* }\end{array}$} & 2009 & 0.52 & 0.45 & & & & \\
\hline & 2011 & 0.29 & 0.30 & -43.8 & -34.3 & & \\
\hline & 2013 & 0.67 & 0.64 & 128.3 & 112.7 & & \\
\hline & 2015 & 0.52 & 0.52 & -22.1 & -18.2 & & \\
\hline & 2018 & 0.65 & 0.59 & 25.7 & 13.1 & 123.5 & 96.7 \\
\hline
\end{tabular}




\section{Median retail price \\ (USD) $)^{\dagger}$}

\% price change 2011-2018 (startend PSCM)

*Drug categories include adult dosages of the following:

Green leaf ACTs: Coartem, Combisunate, Lumartem

Non green leaf ACTs (ss only): Lonart ss

Non-green leaf ACTs (ds only): Camosunate, Coartem ds, Combisunate ds, Lonart ds, P-Alaxin

Non-ACT antimalarials: Amalar, Amalar Plus

ss $=$ standard-strength dosage,$d s=$ double-strength dosage

${ }^{+}$Prices in NGN converted to USD using average annual exchange rate in each respective year reported at knoema.com [21]

Compared to previous surveys, the cost of green leaf ACTs increased over the course of the subsidy scheme from 0.91 USD and 0.78 USD in 2011, to 1.47 USD and 1.63 USD in 2018 among pharmacies and PPMVs, respectively (Table 5). Over the same time period, the cost of both standard and double-strength non-green leaf ACTs reduced. Standard strength non-green leaf ACTs dropped in price by 60\% between 2011 and 2018, resulting in a median retail price comparable to green leaf ACTs (though, it should be noted this group is only represented by the ACT, Lonart). Double-strength non-green leaf ACTs dropped in price by $10.6 \%$ in pharmacies and $17.7 \%$ in PPMVs. The retail price of non-ACT antimalarials was much more volatile and doubled in price between 2011 and 2018, however, this is due to a very low retail price in 2011.

Among all providers, it was perceived that consumer ACT choice is influenced most by price (33\%), followed by the opinion of the pharmacist/PPMV (22\%), prior experience using the ACT (21\%) and brand $(12.5 \%)$.

Demand side: $\mathrm{HH}$ survey

$\mathrm{HH}$ treatment seeking and demand for ACTs

When asked what they would do if they had a positive malaria test, HHs mostly reported seeking treatment from public hospitals (65.1\% [60.6-69.4]), followed by PPMVs (34.2\% [30.0-38.7]), private hospitals (24.0\% [20.2-28.1]), and lastly, pharmacies (10.6\% [8.0-13.8]). Seeking treatment from a public hospital was significantly more common among HHs in northern states $(p<0.001)$, while seeking help from the private sector including private hospitals $(p<0.001)$, pharmacies $(p<0.01)$ and PPMVs $(p<0.01)$ was greater among HHs in southern states (Fig. 5). Similarly, use of public hospitals was higher among rural households $(p<0.01)$, while use of private hospitals $(p<0.01)$ and pharmacies $(p<0.05)$ was higher among urban households (Fig. 5).

By income level, seeking treatment from PPMVs was higher among lower income households, falling from $43 \%$ of HHs in the lowest income segment compared to just $4 \% \mathrm{HHs}$ in the highest income segment (Chi-square test for trend: $X$-squared $=16.103, d f=1, p<0.001)$. In contrast, no trend by income level was observed for HHs seeking treatment from pharmacies, but $25 \%$ of the highest income segment sought treatment from pharmacies compared to just $10 \%$ from each of the other income segments, although no pairwise-comparison reached significance due to the lower sample size of the highest income segment. 
Among all households, $62 \%(n=299)$ reported knowing about ACTs. Knowledge of ACTs was significantly lower in the southern states $(42 \%$ versus $74 \%, p<0.001)$ and in lower income households ( $55 \%$ in HHs with < 18000 versus $79 \%$ in HHs with $100,000+$ income, $p$-value $=0.03$ ).

$\mathrm{HH}$ awareness of green-leaf ACTs was $47.0 \%$. These HHs had predominantly heard about green leaf ACTs through the hospital (52.9\%), followed by PPMVs $(23.1 \%)$, adverts $(22.2 \%)$ or pharmacies $(20.4 \%)$. Among these $\mathrm{HHs}$, the majority $(68.4 \%)$ stated that they prefer green leaf ACTs to non-green leaf ACTs, mostly because green leaf ACTs are more trusted ( $76 \%$ of HHs that prefer green-leaf ACTs), and partly because of lower price $(16.9 \%)$ or simply that it is the ACT available at the outlet (12.3\%).

Half of HHs were aware of the brand of antimalarial that they purchased. The most frequent drug purchased by HHs was the non-ACT antimalarial, Artesunate $(18.0 \%$ of HHs), followed by the green leaf ACT, Coartem (16.5\%), and then the non-green leaf ACT, Lonart (11.7\%, Fig. 6). A similar proportion of HHs reported purchasing green leaf brands $(26.3 \%, 95 \% \mathrm{Cl}[22.4-30.5])$, non-green leaf ACT brands $(23.4 \%, 95 \% \mathrm{Cl}[19.7-$ 27.4]) and non-ACT antimalarial brands (29.0\%, 95\% Cl [25.0-33.3]). One-third of HHs reported that they frequently change brand (35.5\%). The main reason for changing brand was availability $(74.1 \%)$, followed by price $(21.8 \%)$ and side effects of the drugs $(4.1 \%)$.

Price of ACTs and impact on consumer choice

Almost two-thirds of HHs (63.9\%) reported that the price of ACTs had increased in the previous 12 months, with $50 \%$ reporting a greater than $10 \%$ increase in price. However, for most HHs this increase did not change their purchase decision and $57.2 \%$ will continue to buy the brand they usually buy. Other HHs would request a cheaper ACT (22.2\%) or any cheaper antimalarial (19.0\%), and just a few would leave the outlet without buying anything $(1.3 \%)$.

\section{Discussion}

Analyses of the 2018 market survey, particularly in relation to previous ACTWatch surveys, show a clear impact of the PSCM in terms of increasing ACT availability and affordability across private sector outlets. ACT availability was almost universal among PPMVs and pharmacies, while availability of green leaf ACTs was very high ( 80\%). In comparison to previous ACTWatch surveys, the availability of ACTs and green leaf ACTs significantly increased over the time period of the subsidy scheme. Interestingly, the improvements in availability were among PPMVs as opposed to pharmacies among which availability remained steady, suggesting the scheme had a particular impact in reaching PPMVs. This is important since PPMVs were most frequently visited by lower income $\mathrm{HHs}$ and by $\mathrm{HHs}$ in rural areas, where the prevalence of malaria is expected to be higher [22-24].

Although supply of ACTs had improved, there was significantly lower ACT availability in northern regions (for both outlet types) and in urban pharmacies compared to rural pharmacies. Pharmaceutical companies stated that since public distribution programmes had been focused in northern regions, the companies and FLBs had 
focused their commercial efforts to the south where greater gains could be made (personal communication, national survey validation workshop).

The growth in availability of green leaf ACTs tailed-off between the 2015 and 2018 surveys, but there was continued growth in availability of ACTs overall. This is indicative of market growth of non-green leaf ACTs and of the ACT market in general. With the termination of the PSCM in 2018, the decline of growth in green-leaf ACTs likely represents a slowing of supply in preparation for the move to an open market. The prominence of non-green leaf ACTs can be seen when analysing the availability and market share of specific brands. Nongreen leaf ACTs had widespread availability and market share comparable to green leaf ACTs, and a similar proportion of $\mathrm{HH}$ seported purchasing each type. As well as having a comparable market share, standardstrength non-green leaf ACTs were also of a comparable price to green leaf ACTs, having had cost reductions over the time period of the PSCM. These cost reductions put them in direct competition with the subsidised green-leaf ACTs. Similarly, the cost of double-strength dosages had also reduced. This is a clear indirect effect of the PSCM in driving down the costs of competitors and increasing affordability of ACTs in general.

For most $\mathrm{HHs}$, however, price was not the main reason affecting their purchase decision. Most HHs that purchased green leaf ACTs did so due to having higher trust in the product, while most HHs in general reported changing brands frequently based on what is available from the outlet at the time. Furthermore, doublestrength ACTs, despite being much higher in price were reported by outlets as having a larger market share than standard-strength (and cheaper) dosages. This suggests that consumers may be swayed more by convenience than price. As well as different dosages, market share had also been gained by non-subsidised brands via innovation in formulation, particularly for children, with brands offering suspension, syrups and dispersible tablet formulations. Green leaf ACTs, on the other hand, were only offered in standard 24 tablet dosages.

A reliance on achieving market share through low-cost means green leaf brands could fail to compete and hold their market share post-PSCM. Since most HHs buy based on availability, there is opportunity for new brands to enter the market, particularly in the absence of competition from green leaf brands. The concern is that this could lead to influx of substandard and/or falsified ACTs. New and existing brands need to meet quality standards and be identifiable as having met these standards. However, the current pre-qualification programme is inaccessible to many smaller companies due to high costs and the time needed to complete the registration process $[25,26]$. While the increasing coverage of ACTs in general is a positive sign, it could also be a cause for concern if local brands increasing their market share are not QA. We observed a high proportion of the topselling brands to be non-QA but the capacity to rigorously test drug quality in a bioequivalence laboratory does not currently exist in Nigeria.

Of further concern is the continued high availability and market share of oral artemisinin monotherapies (AMT). AMTs were well-stocked and appeared amongst in the top-selling brands, while HHs continued to demand them through their purchase decisions. A contributor to this demand may be that one-third of HHs had not heard of ACTs, indicative of a need for effective health communication on the importance of ACTs over AMTs.

Despite these issues, the PSCM has had a clear positive impact on the ACT market by driving prices down and increasing availability and access. Targeting of the Pharmacies and PPMVs through such approaches is important since they make up a significant role in healthcare provision in Nigeria. Private sector outlets, particularly PPMVs, have been reported as the main source for fever treatment-seeking among the general 
population in repeated national demographic and health surveys [14, 27]. In the 2015 ACTWatch survey, PPMVs were estimated to make up the largest share of the ACT market at $76.0 \%$, while pharmacies took up just $2.5 \%$ of the ACT market [15]. In the 2018 market survey, reported use of the private sector was also considerable, with $34 \%$ of HHs visiting a PPMV for treatment of a suspect malaria case (higher in southern states and among lower income $\mathrm{HHs}$ ) and $11 \%$ visiting a pharmacist (higher in urban areas and among the wealthiest income segment). As well as supply of artemisinins, these outlets play a significant role in health education since many HHs learned about ACTs through these providers. The expansion of public-private-partnerships such as the PSCM could thus be key to eliminating malaria in Nigeria and other countries with similar private healthcare provision and demand.

Despite the 2018 market survey not adhering to the planned sample sizes of outlets in different areas, we are confident the analyses presented here are representative of the situation in the field. When the sampling was planned, the number of outlets in the field was unknown and had to be calculated as such. However, once data collection began it was clear where outlets were fewer or greater in number and our sampling adjusted to reflect the on-the-ground situation. Another limitation of our study may be in the comparability of the 2018 market survey with the ACTWatch surveys since sampling methods differed. However, raw data from the ACTWatch surveys related to pharmacies and PPMVs only were extracted to make indicators as comparable as possible. A final limitation is that there is no previous $\mathrm{HH}$ survey with which to compare change in $\mathrm{HH}$ demand for ACTs and purchasing behaviour. Thus, we cannot show whether the PSCM led to an increase in HH demand, knowledge, and ACT choice over time.

Finally, we have focused here only on the market for antimalarials, but a concern with increased supply and demand of ACTs may be their overuse and misuse, both of which contribute to poor treatment outcomes due to misdiagnosis and place undue pressure on the malaria parasite to evolve drug resistance [28-30]. The increased demand and supply of ACTs should be aligned with diagnostic procedures, including what to do upon a negative malaria test. Case management is a holistic approach including both diagnosis and treatment and thus the focus on one aspect may not be optimal for future similar schemes. Thus, understanding of the mRDT and diagnostic market is as equally important as the ACT market.

\section{Conclusions}

The subsidy scheme does appear to have had a significant impact on improving availability and affordability of ACTs and this is twinned with high consumer demand for malaria treatment from private outlets, particularly among PPMVs. As well as having direct impact through supply of the green leaf brands, the scheme has had indirect effects on the market as a whole, through increasing competition and market share of other, non-green leaf brands. With the end of the subsidy scheme, increased competition for market share can be expected and steps need to be taken to ensure these competing brands are of a high quality, and that the market is kept free of substandard and falsified ACTs, and AMTs. Regular monitoring of the post-subsidy, open market is needed to monitor this closely, as well as methods to aid QA-testing of new and existing products.

\section{Abbreviations}

ACT Artemisinin combination therapy 
AMFm Affordable Medicines Facility - Malaria (AMFm)

AMT Artemisinin monotherapy

Cl Confidence interval

FLB First line buyer

GFATM The Global Fund to Fight AIDS, Tuberculosis and Malaria (GFATM)

$\mathrm{HH}$ Household

LGA Local government authority

PPMV Proprietary and Patent Medicine Vendors

PQ Pre-qualified

PSCM Private sector co-payment mechanism

QA Quality-assured

RDT Rapid diagnostic test

\section{Declarations}

\section{Ethics approval and consent to participate}

Ethical approval for the research protocol was granted by the National Health Research Ethics Committee of Nigeria (NHREC) of the Federal Ministry of Health in Nigeria, protocol number: NHERC/01/01/2007-24/10/2018 and approval number: NHERC/01/01/2007-6/11/2018.

\section{Consent for publication}

Not applicable

\section{Availability of data and materials}

The datasets used and/or analysed during the current study are available from the corresponding author on reasonable request.

\section{Competing interests}

The authors declare that they have no competing interests. 


\section{Funding}

The survey was implemented by Malaria Consortium with funding from a SuNMaP 2 Accountable Grant funded by the Foreign, Commonwealth and Development Office (FCDO) of the UK Government. Funding for the consultancy for sub-analysis was from Malaria Consortium, UK.

\section{Author contributions}

HME contributed to data analysis, interpretation of the data and wrote the final draft of the manuscript. RS contributed to data analysis, interpretation of the data and reviewed the final manuscript. PM contributed to data analysis and reviewed the final manuscript. SE contributed to data interpretation and reviewed the final manuscript. KM contributed to study design and management, data interpretation and reviewed the final manuscript. JKT contributed to study conception, design and management, data interpretation and reviewed the final manuscript.

\section{Acknowledgements}

The authors thank Dr Perpetua Uhomoibhi, National Coordination - National Malaria Elimination Programme (NMEP) Nigeria, and Dr. Audu Bala Mohammed, the former National Coordinator; Dr. Nnenna Ogbulafor, Head of Malaria Case Management, NMEP and Dr. Issa Kawu, NMEP Global Fund Project Manager, for helping us understand NMEP's vision and mission and the sustainability plan for malaria case management. We acknowledge the UK Government Foreign, Commonwealth and Development office (FCDO) for the funding of the SuNMaP 2 Accountable Grant and thank Dr. Ebere Anyachukwu, Health Advisor - FCDO, for providing useful insights to understand the policy implications of the survey findings. We are grateful to Stephen Poyer, Senior Research Advisor, PSI for his support in navigating the ACTwatch data sets, and for the support of Sadruddin Imran, Chairman and CEO of Innovision. Finally, we acknowledge the malaria sector private stakeholders for their support and commitment to the government vision for malaria, and to the all the outlet and household participants for their active contributions to this study.

\section{References}

1. World Health Organization. Guidelines for the treatment of malaria - 3rd edition. 2015.

2. Mabey D, Peeling RW, Ustianowski A, Perkins MD. Diagnostics for the developing world. Nat Rev Microbiol. 2004;2(3):231-40.

3. Bloland PB. Drug resistance in malaria. Switzerland: World Health Organization; 2001.

4. Newton PN, Caillet C, Guerin PJ. A link between poor quality antimalarials and malaria drug resistance? Expert Rev Anti Infect Ther. 2016 Jun 2;14(6):531-3.

5. Gardiner C, Biggar RJ, Collins WE, Nkrumah FK. Malaria in urban and rural areas of southern Ghana: a survey of parasitaemia, antibodies, and antimalarial practices. Bull World Health Organ. 1984;62(4):60713. 
6. Deutsch-Feldman M, Brazeau NF, Parr JB, Thwai KL, Muwonga J, Kashamuka M, et al. Spatial and epidemiological drivers of Plasmodium falciparum malaria among adults in the Democratic Republic of the Congo. BMJ Glob Heal. 2020 Jun 1;5(6):e002316.

7. Campbell J, Dussault G, Buchan H, Pozo-Martin F, Guerra Arias M, Leone C, et al. A universal truth: No health without a workforce. Global Health Workforce Alliance, World Health Organization; 2013.

8. The Global Fund. Technical Brief: Malaria Case Management in the Private Sector [Internet]. The Global Fund; 2019. Available from: https://www.theglobalfund.org/media/5722/core_malariaprivatesector_technicalbrief_en.pdf.

9. Bennett A, Avanceña ALV, Wegbreit J, Cotter C, Roberts K, Gosling R. Engaging the private sector in malaria surveillance: a review of strategies and recommendations for elimination settings. Malar J. 2017;16(1):252.

10. Akulayi L, Alum A, Andrada A, Archer J, Arogundade ED, Auko E, et al. Do anti-malarials in Africa meet quality standards? The market penetration of non quality-assured artemisinin combination therapy in eight African countries. Malar J. 2017;16(1):204.

11. World Health Organization. Procedure for prequalification of pharmaceutical products. WHO Tech Rep Ser. 2011 ;No. 961.

12. AMFm Independent Evaluation Team. Independent Evaluation of Phase 1 of the Affordable Medicines Facility - malaria (AMFm). Multi-Country Independent Evaluation Report: Final Report. Calverton, Maryland and London; 2012.

13. Akulayi L, Alum A, Andrada A, Archer J, Arogundade ED, Auko E, et al. What happened to anti-malarial markets after the Affordable Medicines Facility-malaria pilot? Trends in ACT availability, price and market share from five African countries under continuation of the private sector co-payment mechanism. Malar J. 2017;16(1):173.

14. Nigeria National Population Commission, ICF International. Nigeria Demographic and Health Survey 2018 [Internet]. Abuja, Nigeria and Rockville, Maryland, USA; 2019. Available from:

https://dhsprogram.com/publications/publication-fr359-dhs-final-reports.cfm.

15. ACTwatch Group SFH. ACTwatch Study Reference Document: The Federal Republic of Nigeria Outlet Survey 2015. Washington DC; 2015.

16. Pharmacists Council of Nigeria. Patent and Proprietary Medicine Vendors (PPMVs). REGISTRATION AND LICENSING. Procedures and Guidelines [Internet]. 2020 [cited 2021 Jun 2]. Available from: https://www.pcn.gov.ng/registration-and-licensing/patent-and-proprietary-medicine-vendors-ppmv/.

17. LimeSurvey GmbH. LimeSurvey: An Open Source survey tool [Internet]. Hamburg, Germany: LimeSurvey GmbH; Available from: http://www.limesurvey.org.

18. SPSS Inc. SPSS for Windows, Version 16.0. Chicago: SPSS Inc..

19. R Core Team. R: A language and environment for statistical computing. [Internet]. Vienna, Austria: $R$ Foundation for Statistical Computing; 2021. Available from: https://www.r-project.org/.

20. The Malaria Atlas Project (map). ACTWATCH [Internet]. [cited 2021 Aug 2]. Available from: https://malariaatlas.org/actwatch/.

21. Knoema. Nigeria - Official exchange rate [Internet]. [cited 2021 Aug 31]. Available from: https://knoema.com/atlas/Nigeria/topics/Economy/Financial-Sector-Exchange-rates/Exchange-rate. 
22. Morakinyo OM, Balogun FM, Fagbamigbe AF. Housing type and risk of malaria among under-five children in Nigeria: evidence from the malaria indicator survey. Malar J [Internet]. 2018 Aug 28;17(1):311. Available from: https://pubmed.ncbi.nlm.nih.gov/30153834.

23. Okunlola OA, Oyeyemi OT. Spatio-temporal analysis of association between incidence of malaria and environmental predictors of malaria transmission in Nigeria. Sci Rep [Internet]. 2019;9(1):17500. Available from: https://doi.org/10.1038/s41598-019-53814-x.

24. Babalola OJ, Ajumobi O, Ajayi IO. Rural-urban disparities and factors associated with delayed careseeking and testing for malaria before medication use by mothers of under-five children, Igabi LGA, Kaduna Nigeria. Malar J [Internet]. 2020;19(1):294. Available from: https://doi.org/10.1186/s12936-02003371-w.

25. Huang $Y$, Pan K, Peng D, Stergachis A. A qualitative assessment of the challenges of WHO prequalification for anti-malarial drugs in China. Malar J. 2018;17(1):149.

26. Dellepiane N, Wood D. Twenty-five years of the WHO vaccines prequalification programme (1987-2012): lessons learned and future perspectives. Vaccine. 2013/12/02. 2015 Jan 1;33(1):52-61.

27. Nigeria National Population Commission, ICF International. Nigeria Demographic and Health Survey 2013 [Internet]. Abuja, Nigeria and Rockville, Maryland, USA; 2014. Available from: https://dhsprogram.com/publications/publication-fr293-dhs-final-reports.cfm?cssearch=342433_1.

28. Nwokolo E, Ujuju C, Anyanti J, Isiguzo C, Udoye I, Bongos-lkwue E, et al. Misuse of Artemisinin Combination Therapies by Clients of Medicine Retailers Suspected to Have Malaria Without Prior Parasitological Confirmation in Nigeria. Int J Heal Policy Manag [Internet]. 2018;7(6):542-8. Available from: https://www.ijhpm.com/article_3434.html.

29. Visser T, Bruxvoort K, Maloney K, Leslie T, Barat LM, Allan R, et al. Introducing malaria rapid diagnostic tests in private medicine retail outlets: A systematic literature review. PLoS One. 2017;12(3):e0173093.

30. Odugbemi B, Ezeudu C, Ekanem A, Kolawole M, Akanmu I, Olawole A, et al. Private sector malaria RDT initiative in Nigeria: lessons from an end-of-project stakeholder engagement meeting. Malar $\mathrm{J}$ [Internet]. 2018;17(1):70. Available from: https://doi.org/10.1186/s12936-018-2222-8.

\section{Figures}




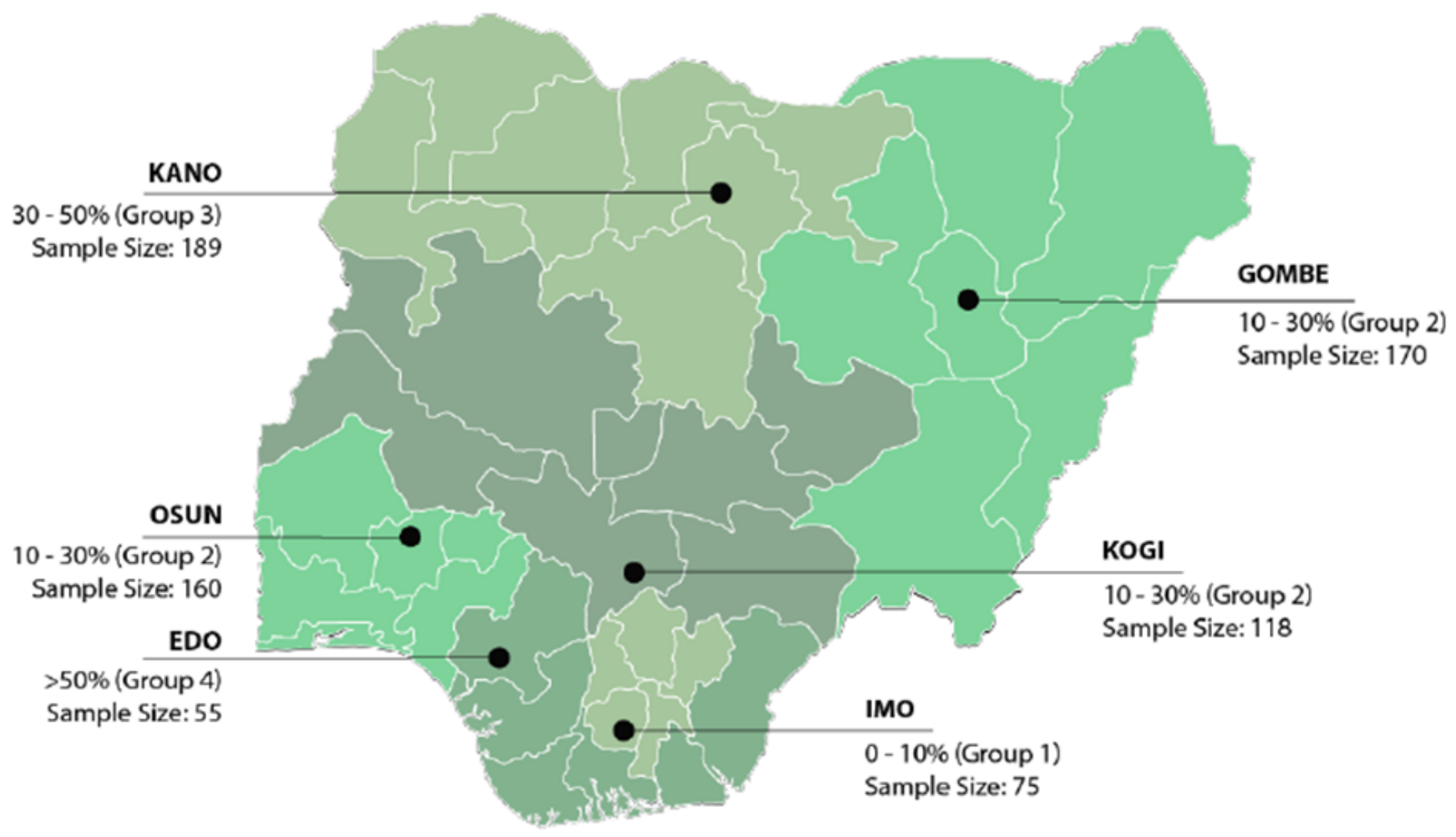

\section{Figure 1}

Sampling locations of the outlet survey showing malaria prevalence grouping and outlet sample size. 
A)

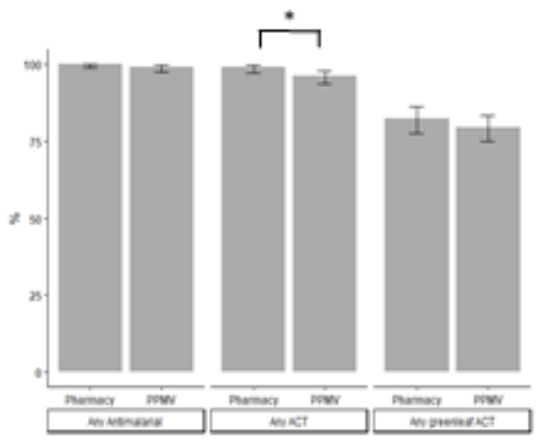

B)
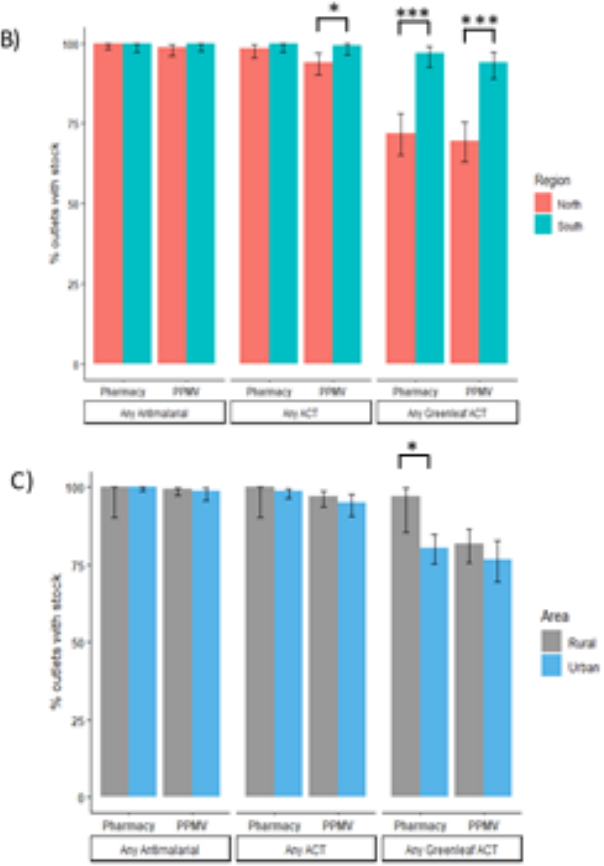

Figure 2

Coverage of different antimalarial drug types in Pharmacies and PPMVs A) nationwide, B) by region, and C) by area. Asterisks show significant differences between sub-groups, ${ }^{*} p<0.05,{ }^{* \star *} p<0.001$ 
A)

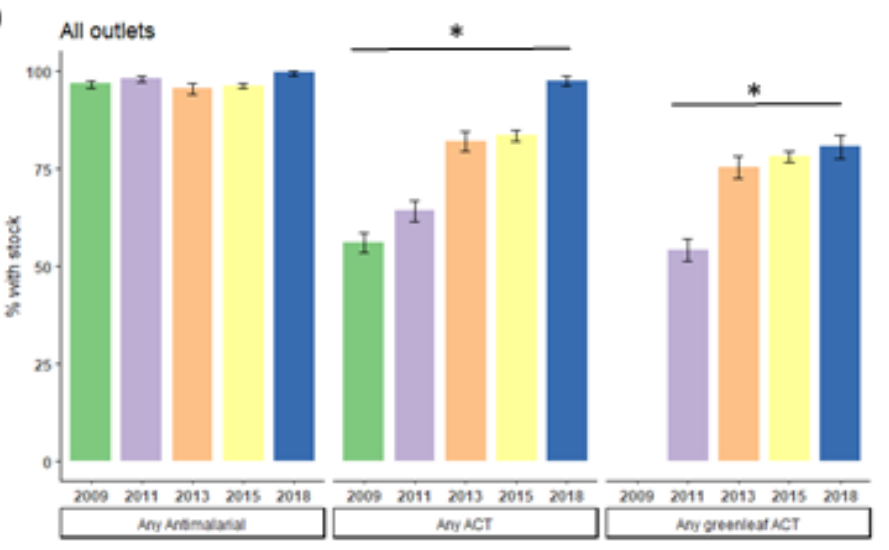

B)

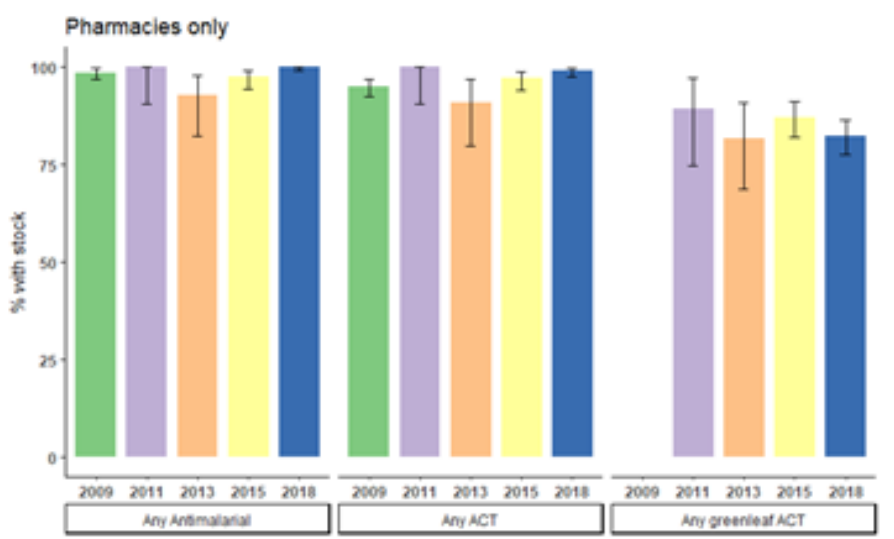

C)

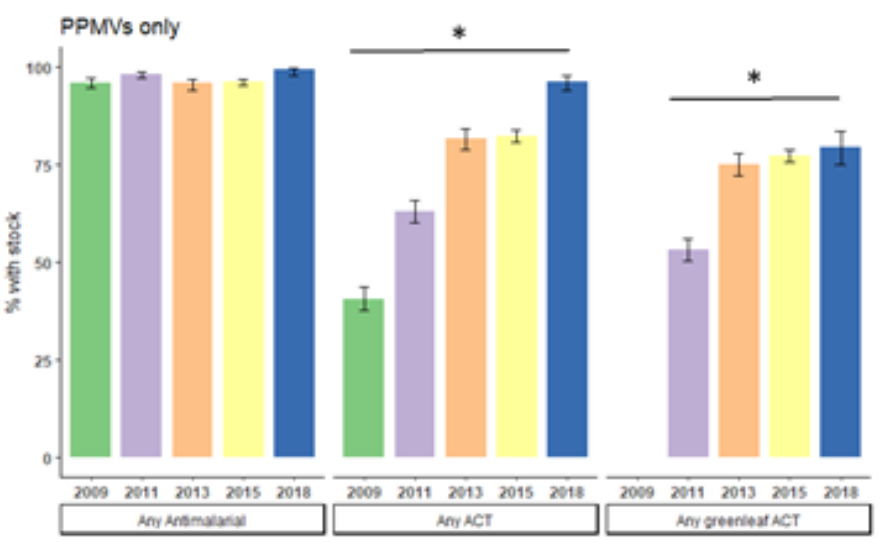

Figure 3

Availability of different antimalarial types across ACTWatch surveys (2009-2015) and the 2018 market survey, including A) all pharmacies and PPMVs, B) pharmacies only, and C) PPMVs only. *test for trend $p<0.001$ 

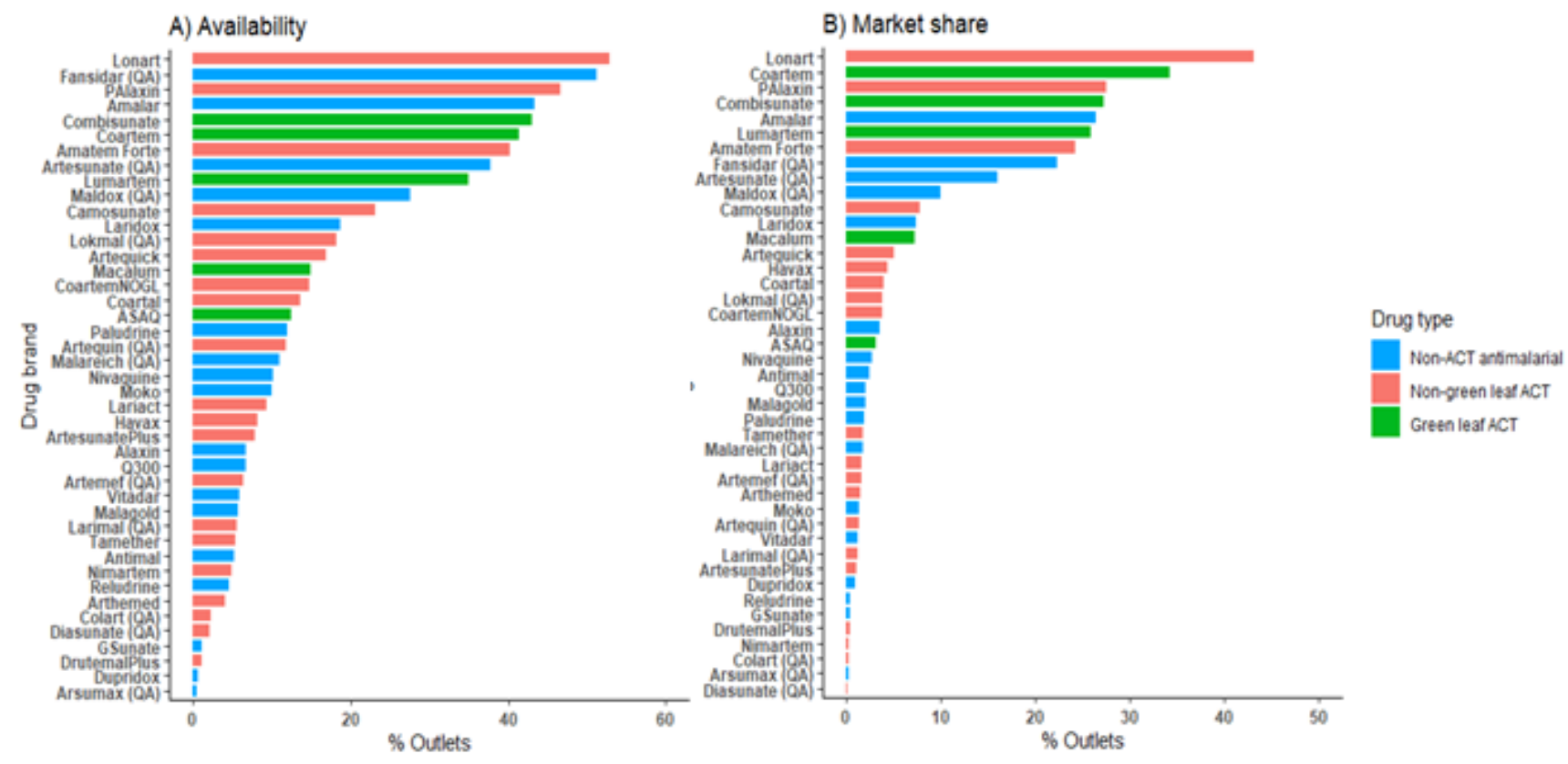

\section{Figure 4}

Availability and market share of different antimalarial brands. A) Availability of brands across outlets on the day of the survey. B) Market share of brands as reported by outlet staff. Bars show \% outlets that named each given brand in the top 5 best-selling brands from their outlet. Includes pharmacies and PPMVs.

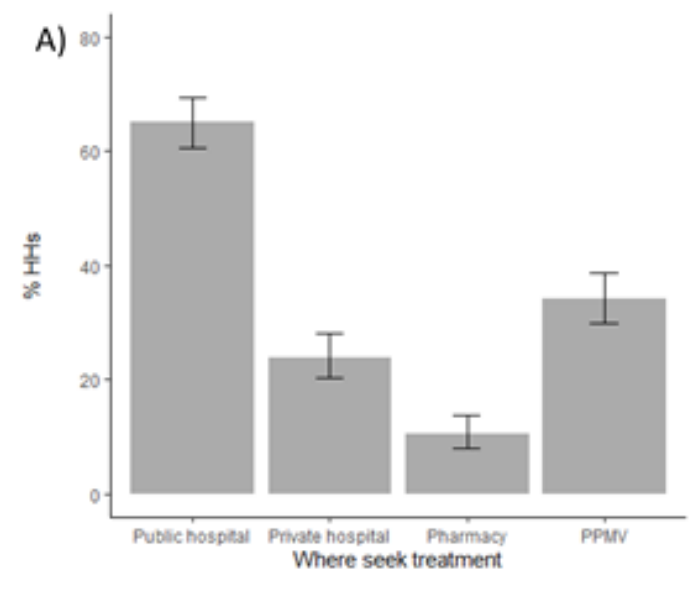

B)
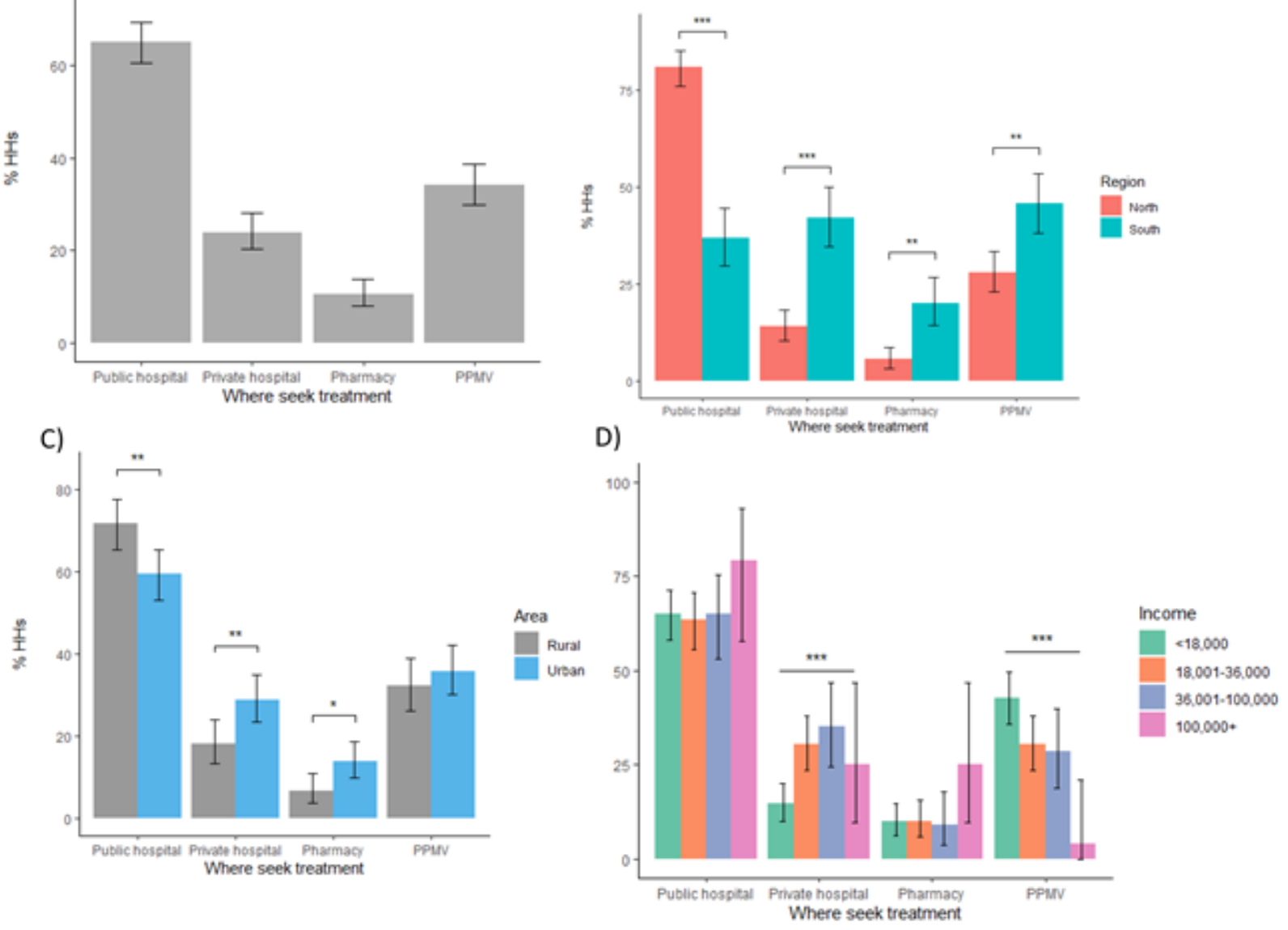

Figure 5 
Treatment seeking behaviour following a positive malaria test among $\mathrm{HHs}$ A) nationwide, $\mathrm{B}$ ) by region, C) by area, and D) by monthly income. Asterisks show significant differences between sub-groups found either by binomial test for difference in proportions or chi-square test for trend: ${ }^{\star} p<0.05,{ }^{*} \mathrm{p}<0.01,{ }^{\star \star \star} \mathrm{p}<.001$

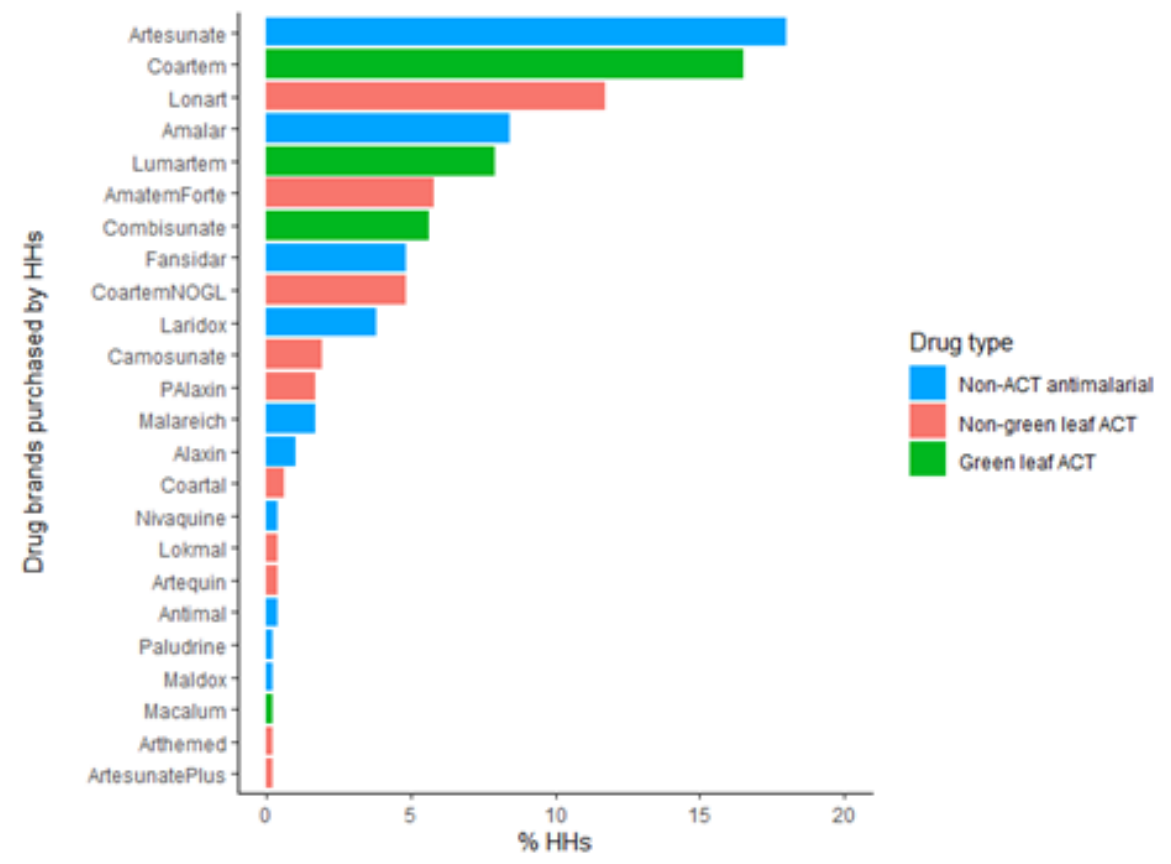

\section{Figure 6}

Drug brands purchased by each HH. No HHs reported purchasing: Arsumax, Artemef, Artequick, ASAQ, Colart, Diasunate, DrutemalPlus, Dupridox, GSunate, Havax, Lariact, Larimal, Malagold, Moko, Nimartem, Pamametre, Q300, Reludrine, Tamether, Vitadar.

\section{Supplementary Files}

This is a list of supplementary files associated with this preprint. Click to download.

- SuppinfoAntimalarialdrugcategorisationfinal.docx 